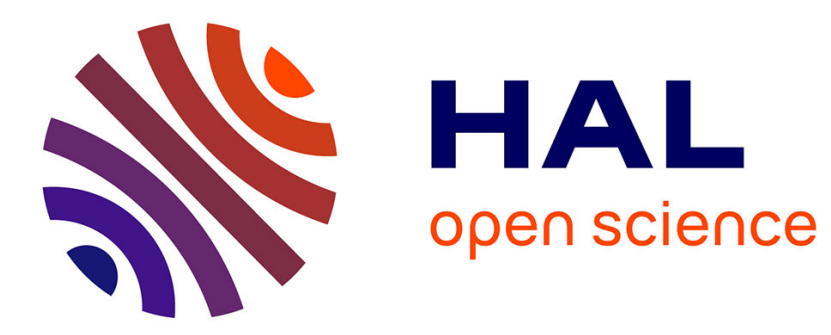

\title{
Organo-apatites for lead removal from aqueous solutions: A comparison between carboxylic acid and aminophosphonate surface modification
}

Sanaa Saoiabi, Karima Achelhi, Sylvie Masse, Ahmed Saoiabi, Abdelaziz Laghzizil, Thibaud Coradin

\section{To cite this version:}

Sanaa Saoiabi, Karima Achelhi, Sylvie Masse, Ahmed Saoiabi, Abdelaziz Laghzizil, et al.. Organoapatites for lead removal from aqueous solutions: A comparison between carboxylic acid and aminophosphonate surface modification. Colloids and Surfaces A: Physicochemical and Engineering Aspects, 2013, 419, pp.180-185. 10.1016/j.colsurfa.2012.12.005 . hal-01461412

\author{
HAL Id: hal-01461412 \\ https://hal.science/hal-01461412
}

Submitted on 14 Nov 2019

HAL is a multi-disciplinary open access archive for the deposit and dissemination of scientific research documents, whether they are published or not. The documents may come from teaching and research institutions in France or abroad, or from public or private research centers.
L'archive ouverte pluridisciplinaire HAL, est destinée au dépôt et à la diffusion de documents scientifiques de niveau recherche, publiés ou non, émanant des établissements d'enseignement et de recherche français ou étrangers, des laboratoires publics ou privés. 


\section{Organo-apatites for lead removal from aqueous solutions: a comparison between carboxylic acid and aminophosphonate surface modification}

Sanaa Saoiabi, ${ }^{\mathrm{a}, \mathrm{b}}$ Karima Achelhi, ${ }^{\mathrm{a}, \mathrm{b}}$ Sylvie Masse, ${ }^{\mathrm{a}}$ Ahmed Saoiabi, ${ }^{\mathrm{b}}$ Abdelaziz Laghzizil, ${ }^{\mathrm{b}, *}$ and Thibaud Coradin ${ }^{\mathrm{a}, *}$

a'UPMC Univ P6 ; CNRS, Chimie de la Matière Condensée de Paris, Collège de France, 75005 Paris, France.

${ }^{\mathrm{b}}$ Laboratoire de Chimie Physique Générale, Faculté des Sciences, Université Mohamed V-Agdal, BP.1014 Rabat, Morocco

*Corresponding authors :

T. Coradin ; e-mail : thibaud.coradin@upmc.fr; tel : 33-144271528 ; fax :33-144274769

A. Laghzizil ; e-mail : laghzizi@ fsr.ac.ma; tel/fax : 212-537775440 
Abstract : Organo-apatites were prepared by in situ incorporation of adipic acid, citric acid and nitrilotris(methylene)triphosphonic acid. The resulting powders consist of poorly-crystalline nanosized apatites with organic content in the 2-8 wt \% range. All materials exhibit faster sorption rate and higher sorption capacity for $\mathrm{Pb}^{2+}$ in acidic solutions compared to the pure apatite. This is especially true for carboxylate-modified powders that exhibit the highest-to-date maximum lead sorption capacity $\left(\approx 1 \mathrm{~g} \cdot \mathrm{g}^{-1}\right)$. These properties can be correlated with the ability of introduced organic moieties to modify the acido-basic properties of the material surface and to form stable complexes with $\mathrm{Pb}^{2+}$.

Keywords : hydroxyapatite ; heavy metals ; trisphosphonates ; carboxylic acids 


\section{Introduction}

The potentialities of hydroxyapatite $\left(\mathrm{Ca}_{10}\left(\mathrm{PO}_{4}\right)_{6}(\mathrm{OH})_{2}\right)$ materials for the treatment of wastewater and contaminated soils is now well-accepted [1,2]. Hydroxyapatite combines the advantage of being available in large amounts (i.e. natural phosphate rocks) and environmentally-benign [3]. Moreover, it exhibits a reactive surface towards metal cations and polar organic molecules sorption [4,5]. However, natural apatite powders are often constituted of large grains and therefore suffer from low specific surface area [6,7]. Synthetic apatites can be obtained at the nanoscale but corresponding processes often involve the use of organic solvents or surfactants [8], and the resulting powders exhibit low colloidal stability in water [9].

A particularly promising approach to address these limitations relies on the addition of specific additives to a solution of calcium and phosphate ions with the aim of controlling both the growth of apatite crystals and the chemical nature of the particle surface $[10,11]$. Two types of additives have been more specifically studied: organo-phosphonates and carboxylic acids. In the first case, phosphate groups of the additive can substitute inorganic phosphates within the apatite structure, while the organic moieties are located on the particle surface [12,13]. For instance, 2aminoethylphosphoric acid can be used to obtain apatite nanopowders with high colloidal stability in water and cytocompatibility [14] The influence of carboxylic acids on apatite growth was also studied, but the surface properties of the resulting powders were not investigated in details [15].

In this context, we have evaluated here two carboxylic acids, adipic and citric acid, and an organo-phosphonate molecule, nitrilotris(methylene)triphosphonic acid, as potential additives to synthetic apatite in order to prepare modified apatites with high capacity for metal sorption. Carboxylic acids are well-known ligands for divalent metals [18], and we hypothesized that di- or tri-acids should be preferred as at least one of the carboxylic function should be in interaction 
with the apatite surface. Accordingly, nitrilotris(methylene)triphosphonic acid has a strong affinity for a wide range of inorganic cations [19], and bears three phosphate groups. Moreover, these three molecules have the advantage of being water soluble, cheap and environmentalfriendly [20]. We show here that carboxylic acids can be incorporated in reasonably high amounts and very significantly increase the material sorption rate and efficiency for $\mathrm{Pb}^{2+}$, reaching the highest sorption capacity so far reported for apatite-based sorbents. The presence of the aminophosphonate also increases sorption rate and maximum capacity but to a much lower extent, that can be related to the lower amount of possible ligand incorporation. We also show that the presence of the organic functions significantly impact on the acido-basic properties of the materials and therefore on their reactivity towards lead ions

\section{Materials and methods}

\subsection{Chemicals.}

Calcium hydroxyde $\left(\mathrm{Ca}(\mathrm{OH})_{2}\right)$, ammonium di-hydrogenophosphate $\left(\mathrm{NH}_{4} \mathrm{H}_{2} \mathrm{PO}_{4}\right)$ aqueous solution (30 wt\%), adipic acid, citric acid, nitrilotris(methylene)triphosphonic acid (NTP) aqueous solution $(50 \mathrm{wt} \%)$ and lead nitrate $\mathrm{Pb}\left(\mathrm{NO}_{3}\right)_{2}$ were purchased from Aldrich.

\subsection{Synthesis of organo-apatite sorbents.}

The pure hydroxyapatite (HAp) was prepared by a modified chemical wet method previously reported, based on the neutralization of 1.67 mole of $\mathrm{Ca}(\mathrm{OH})_{2}$ in aqueous solution $(1.67 \mathrm{M})$ by 1 mole of $\mathrm{NH}_{4} \mathrm{H}_{2} \mathrm{PO}_{4}$ in aqueous solution [21]. The carboxylate-modified hydroxyapatites were obtained as previously described, by addition of adipic acid (a-HAp) or citric acid (c-HAp) to the $\mathrm{Ca}(\mathrm{OH})_{2}$ solution in a $0.25: 1$ molar ratio, before neutralization [17]. The NTP-modified hydroxyapatites were obtained by adaptation of a procedure developed for surface modification 
of natural phosphate rocks [22], by adding 0.025 moles (2.5N-HAp) and 0.05 moles (5N-HAp) of NTP to 0.975 mole and 0.950 mole of $\mathrm{NH}_{4} \mathrm{H}_{2} \mathrm{PO}_{4}$, respectively, before neutralization of the $\mathrm{Ca}(\mathrm{OH})_{2}$ solution. In all cases, powders were recovered by centrifugation, thoroughly washed with deionized water and was dried overnight at $100^{\circ} \mathrm{C}$ in an oven.

\subsection{Powder characterization.}

The crystalline phases were identified using a powder X-ray diffractometer (XRD) (Philips PW131 diffractometer), using the $\mathrm{Cu} \mathrm{K} \alpha$ radiation. Infrared spectra were recorded from $400 \mathrm{~cm}^{-1}$ to $4000 \mathrm{~cm}^{-1}$ on a Brüker IFS 66v Fourier transform spectrometer using $\mathrm{KBr}$ pellets. Transmission electron microscopy (TEM) was performed on a Tecnai Spirit G2 operating at 100 $\mathrm{kV}$. The $\mathrm{N}_{2}$ adsorption-desorption isotherms for dried powders were obtained by multi-point $\mathrm{N}_{2}$ gas sorption experiments at $77 \mathrm{~K}$ using a Micromeritics ASAP 2010 instrument. The specific surface areas were calculated according to the Brunauer-Emmett-Teller (BET) method using adsorption data in the relative pressure range from 0.05 to 0.25 . Thermogravimetry analysis (TGA) was carried out in airflow using a TA Instruments Netzsch STA-409EP apparatus. The thermal measurements were conducted from $30^{\circ} \mathrm{C}$ to $1000^{\circ} \mathrm{C}$ with $10^{\circ} \mathrm{C} / \mathrm{min}$ as heating rate. The sample chemical composition was obtained by inductively coupled plasma (ICP) emission spectroscopy (ICPS-7500, Shimadzu, Japan) and by elemental analysis from the CNRS Centre d'Analyse (Vernaison, France).

\subsection{Lead sorption experiments and modelling.}

Aqueous solutions containing $\mathrm{Pb}^{2+}$ ions at various concentrations were prepared from lead nitrate in distilled water. The $\mathrm{pH}$ was adjusted to 5 using nitric acid. Lead sorption kinetics were measured in a $500 \mathrm{~mL}$ thermostatted reactor at $25^{\circ} \mathrm{C}$ using $200 \mathrm{~mL}$ of lead solution at a 100 
mg.mL $L^{-1}$ lead concentration with $400 \mathrm{mg}$ of sorbent. The mixture was stirred at $400 \mathrm{rpm}$ using a mechanical stirrer (EUROSTAR digital IKA) to provide reproducible and homogeneous mixing. Adsorption isotherms were determined similar conditions by mixing $100 \mathrm{~mL}$ of metal-containing solution with $200 \mathrm{mg}$ of adsorbent at $25^{\circ} \mathrm{C}$. Based on kinetics data, the mixture was stirred for $3 \mathrm{~h}$ to allow the adsorption to reach equilibrium. The initial metal concentration was varied from 10 to $2000 \mathrm{mg} . \mathrm{L}^{-1}$. The variation of the $\mathrm{pH}$ of the contaminated aqueous solutions during metal adsorption was measured for all adsorbents using a $\mathrm{pH}$ meter, with experimental variations in a $2 \%$ range. In bot studies, aliquots of the supernatant solution were taken with a $2 \mathrm{~mL}$ propylene syringe equipped with a $0.45 \mu \mathrm{m}$ filter. The amount of adsorbed lead per gram of adsorbent $q_{t}$ (in mg. $\mathrm{g}^{-1}$ ) at time $t$ was calculated as follows (eq. 1):

$q_{t}=\frac{C_{0}-C_{t}}{m} V$

where $C_{0}$ and $C_{t}$ are the metal ion concentration (in $\mathrm{mg} . \mathrm{L}^{-1}$ ) in the liquid phase initially and at any time $t$ respectively, $m$ is the mass of adsorbent (in $\mathrm{g}$ ) in the solution, and $V$ is the solution volume (in L). All measurements were performed in triplicate and experimental errors were found below 5\%. Lead was chemically analyzed by inductively coupled plasma (ICP) emission spectroscopy (ICPS-7500, Shimadzu, Japan).

In order to determine the sorption rate constant, the Lagergren pseudo-first order model was applied to the experimental data [23]. The corresponding equation can be expressed as (eq. 2):

$$
\log \left(q_{e}-q_{t}\right)=\log q_{e}-\frac{k}{2.303} t
$$

where $q_{e}$ is the amount of adsorbed lead per gram of adsorbent (in $\mathrm{mg} \cdot \mathrm{g}^{-1}$ ) at equilibrium, and $k$ is the pseudo-first order rate constant (in s ${ }^{-1}$ ). 
Langmuir and Freundlich models are commonly used to study sorption processes [24]. The Langmuir adsorption model is based on the assumption that a maximum uptake exists, corresponding to a saturated monolayer of sorbed molecules on the adsorbent surface. In the case of composite materials, the Freundlich adsorption model is more adapted as it assumes that adsorption occurs on a heterogeneous surface through a multilayer adsorption mechanism. According to the Freundlich model, the adsorbed amount increases with the concentration according to (eq. 3):

$q_{e}=q_{e, \max } \frac{K_{F} C_{e}^{\beta}}{1+K_{F} C_{e}^{\beta}}$

where $K_{F}$ is the equilibrium constant of the adsorption reaction and $\beta$ is the empirical parameter related to the intensity of adsorption, which varies with the heterogeneity of the material. When $\beta$ values are from 0.1 to 1 , the adsorption conditions are favorable.

The fitting procedure of kinetics and isotherm data was performed using the Kaleidagraph software that provide coefficient of determination $R^{2}$.

\section{Results and discussion}

\subsection{Characterization of the organo-apatite powders.}

The chemical composition of the NTP-HAp, a-HAp and c-HAp materials was first studied by CHNOS elementary microanalysis technique and ICP-AES (Table 1). The Ca:P molar ratio of all samples was similar and close to 1.60 , except for the a-HAp material. The $\% \mathrm{C}$ and $\% \mathrm{~N}$ indicate that NTP and carboxylic acid incorporation in moderate amounts, as expected from the initial ligand:Ca ratios.

TGA curves for the powders shown in Figure 1. For pure HAp, a continuous weight loss is observed between $100^{\circ} \mathrm{C}$ and $700^{\circ} \mathrm{C}$ corresponding to $c a .6 \mathrm{wt} \%$, corresponding to loss of 
physically adsorbed water $\left(100^{\circ} \mathrm{C}-200^{\circ} \mathrm{C}\right)$, structural water and organic traces $\left(200^{\circ} \mathrm{C}-500^{\circ} \mathrm{C}\right)$ and $\mathrm{CO}_{2}$ upon decarbonatation $\left(500-800^{\circ} \mathrm{C}\right)$. For carboxylate-modified apatite, the organic degradation is evidenced in the $200-500^{\circ} \mathrm{C}$ domain, corresponding to $\mathrm{ca} .4 \mathrm{wt} \%$ and $8 \mathrm{wt} \%$ for aHAp and c-HAp, respectively. For NTP, the organic degradation is expected to occur from $300^{\circ} \mathrm{C}$ to $700^{\circ} \mathrm{C}$ [25], representing ca. $2 \mathrm{wt} \%$ and $3 \mathrm{wt} \%$ for $2.5 \mathrm{~N}-\mathrm{HAp}$ and $5 \mathrm{~N}-\mathrm{HAp}$, respectively

XRD patterns of as-prepared materials after drying at $100^{\circ} \mathrm{C}$ are shown in Figure 2. A poorly crystalline structure is obtained for all products, with typical diffraction peaks at $2 \theta \approx$ $32^{\circ}, 33^{\circ}$ and $34^{\circ}$ corresponding to the (211), (112) and (300) planes of the apatite structure (JCPDS No. 09-0432). A significant broadening of these diffraction peaks suggests reduction in apatite crystallinity in the presence of organic molecules, especially for a-HAp and c-HAp.

Infrared spectra of the as-prepared materials are shown in Figure 3. On the pure HAp sample, vibrational bands at $c a .3570 \mathrm{~cm}^{-1}$ and $630 \mathrm{~cm}^{-1}$ are assigned to the $\mathrm{OH}$ groups, while sharp peaks at ca. 1090, 1030, 960, 605 and 565 and $470 \mathrm{~cm}^{-1}$ can be attributed to $\mathrm{PO}_{4}$ vibration. Vibration bands in the $1400-1450 \mathrm{~cm}^{-1}$ wavenumber range correspond to carbonate ions that could originate from the dissolution of surrounding $\mathrm{CO}_{2}$ during aqueous precipitation. ${ }^{1}$ For aHAp, the band in the $1600-1650 \mathrm{~cm}^{-1}$ should correspond to $\mathrm{d}(\mathrm{H}-\mathrm{O}-\mathrm{H})$ of adsorbed water, the $\mathrm{n}_{\text {asym }}\left(\mathrm{COO}^{-}\right)$vibration is identified near $1550 \mathrm{~cm}^{-1}$ and the $\mathrm{n}_{\text {sym }}\left(\mathrm{COO}^{-}\right)$is expected near $1400 \mathrm{~cm}^{-}$ ${ }^{1}$, overlapping with carbonate bands. In the case of c-HAp, because of the higher content in organic acid incorporated, this latter band is clearly visible at $1420 \mathrm{~cm}^{-1}$ together with the asymmetric band shifted to higher wavenumber $\left(\mathrm{ca}\right.$. at $\left.1590 \mathrm{~cm}^{-1}\right)$. In the presence of NTP, one may observe the broadening of $\mathrm{PO}_{4}$ bands that is related to the structural disorder and the presence of $\mathrm{R}-\mathrm{PO}_{3}$ groups. Weak peaks in the $1400-1450 \mathrm{~cm}^{-1}$ wavenumber range can correspond to organic $\mathrm{C}-\mathrm{C}$ vibrations although they also overlap with carbonate bands. The 
grafting of NTP is also supported by the presence of a wide band in the $2500-3000 \mathrm{~cm}^{-1}$, resulting from the overlap of the $\mathrm{C}-\mathrm{H}, \mathrm{N}-\mathrm{C}$ and $\mathrm{C}-\mathrm{P}$ stretching band of NTP.

TEM studies indicate that the HAp reference powder consists of loose aggregates of nanoplatelets with an average size of $100 \mathrm{~nm}$ (Figure 4a). In contrast, all samples obtained with organics consist of aggregated particles, with largest in-plane in the $30 \pm 5 \mathrm{~nm}$ size range (Figure 4b-e). At high magnification, the crystalline planes of the apatite particles are clearly evidenced (Figure 4f). This decrease in particle size reflects the ability of the organic additives to influence the growth of apatite particles, either by complexation of calcium ions by carboxylates or by partial substitution of phosphate groups within the mineral structure for NTP.

Figure 5 shows the full $\mathrm{N}_{2}$ adsorption-desorption isotherms of all solids dried at $100^{\circ} \mathrm{C}$. These isotherms correspond to mesoporous materials due to inter-particle porosity. As indicated in Table 1, $S_{B E T}$ for the pure HAp sample is slightly enhanced in the presence of adipic acid, citric acid and low NTP content, reflecting the decrease in apatite particle size. However, the presence of organic molecules may modify the particle packing within the powder, as suggested by agregates formation observed by TEM, and also block the access of $\mathrm{N}_{2}$ gas to the porosity, decreasing the powder specific surface area, as observed for $5 \mathrm{~N}-\mathrm{HAp}$. At this stage, it is important to note that attempts to prepare materials with higher NTP content led to a non-homogeneous powders with low $S_{B E T}\left(\right.$ i.e. $90 \mathrm{~m}^{2} \cdot \mathrm{g}^{-1}$ for $10 \% \mathrm{~N}-\mathrm{HAp}$ ), that were not investigated further.

\subsection{Lead sorption experiments.}

The kinetics of the $\mathrm{Pb}$ sorption process were first studied at a $100 \mathrm{mg} \cdot \mathrm{mL}^{-1}$ concentration. As shown in Figure 6, the presence of carboxylates and NTP speed up the sorption process, but 
no significant effect of the nature of acid structure or NTP amount could be evidenced. When the two systems are compared, the carboxylate-modification appears more efficient in enhancing the sorption rate. The pseudo first-order Lagergren model reveal suitable to reproduce the experimental data $\left(R^{2}\right.$ kin $\left.\geq 0.99\right)$. Extracted parameters are gathered in Table 2 . They show that, in these conditions, the lead sorption capacity at equilibrium $q_{e}$ is very similar for all materials, independently of surface modification, but that the sorption rate $k$ is increased by a factor of 4 in the presence of NTP and of $c a .250$ in the presence of carboxylate.

Sorption isotherms were then determined and plotted as amount of sorbed lead par $\mathrm{g}$ of material as a function of lead concentration in solution at the sorption equilibrium (Figure 7). For carboxylate-modified powders, the experimental maximum capacity was very significantly increased, especially for a-HAp. The experimental maximum capacity also increases markedly from HAp to 2.5N-HAp then moderately with increasing organic content. The Freundlich equation was found suitable to obtain a reasonable curve fitting of the experimental data $\left(R^{2}{ }_{i s o} \geq\right.$ 0.99) (Table 2). Calculated $q_{e, \max }$ values reflect the noticeable increase in sorption capacity upon NTP and carboxylate incorporation, up to 5-fold for a-HAp. When calculated by available surface area, it is worth noting that a clear improvement of sorption capacity is obtained from $2.5 \mathrm{~N}-\mathrm{HAp}$ $\left(2.8 \mathrm{mg} \cdot \mathrm{cm}^{-3}\right)$ to $5 \mathrm{~N}-\mathrm{HAp}\left(3.6 \mathrm{mg} \cdot \mathrm{cm}^{-3}\right)$. It is important to point out that these values are higher than previously reported data in the literature for natural and synthetic apatites, as well as for other sorbents [26]. Interestingly introduction of carboxylates significantly lower the $\beta$ value whereas no variation is observed for NTP-modified apatites. This reflects the fact that carboxylate functions have a lower affinity for $\mathrm{Pb}^{2+}$ than the apatite surface. In contrast, the $\mathrm{Pb}^{2+}$ binding functions of NTP are phosphate groups, similarly to reactive groups of apatite. 


\subsection{Acido-basic properties of organo-apatites.}

To clarify the sorption process, the evolution of solution $\mathrm{pH}$ was followed during the course of the sorption process. As shown in Fig 8, in the absence of $\mathrm{Pb}^{2+}$, the $\mathrm{pH}$ of powder suspensions strongly increases from 5 to 7.9 for HAp and more moderately to 7.0 and 6.1 for a-HAp and cHAp, respectively. The presence of NTP also decreases the equilibrium $\mathrm{pH}$ to 7 and 6.3 for $2.5 \mathrm{~N}$ HAp and 5N-HAp, respectively. Moreover, the course of $\mathrm{pH}$ evolution is also different, with a first period of moderate increase, for $5 \mathrm{~N}-\mathrm{HAp}$. The increase of $\mathrm{pH}$ for pure apatite corresponds to two main processes: protonation of $\mathrm{PO}_{4}{ }^{-}$groups and surface dissolution leading to calcium, phosphate and hydroxy ions release [27]. The presence of organic ligands can impact these processes by limiting the water access and therefore the reactivity of the apatite surface [28], and by releasing protons. Adipic acid has two acidic functions, with $\mathrm{pK}_{\mathrm{a}} 4.4$ and 5.4, and citric acid has three acidic groups, with $\mathrm{pK}_{\mathrm{a}} 3.1,4.8$ and 6.4 , so that each ligand has one carboxylic group at $\mathrm{pH} 5$ that can be deprotonated during the apatite-induced $\mathrm{pH}$ increase. The main forms of NTP at $\mathrm{pH} 5$ are tri- and tetra-deprotonated forms (i.e. $\left.\mathrm{NH}\left[\left(\mathrm{CH}_{2} \mathrm{PO}_{3} \mathrm{H}_{2}\right)\left(\mathrm{CH}_{2} \mathrm{PO}_{3} \mathrm{H}\right)_{3}\right)\right]^{2-}$ and $\left.\left.\mathrm{NH}\left[\left(\mathrm{CH}_{2} \mathrm{PO}_{3} \mathrm{H}\right)_{4}\right)\right]^{3-}\right)^{29}$ and two more protons can be lost when $\mathrm{pH} 7$ is reached. Moreover, it was previously demonstrated that the presence of calcium ions can reduce NTP pKa values (i.e. increase deprotonation) via chelation [29]. Hence it can be proposed that the slower $\mathrm{pH}$ increase observed for $5 \mathrm{~N}-\mathrm{HAp}$ is due to the predominating effect of NTP deprotonation over apatite protonation.

In the presence of $\mathrm{Pb}^{2+}$, the $\mathrm{pH}$ evolution is strongly different (Figure 9). For pure HAp, a continuous increase in $\mathrm{pH}$ is observed but to a much lesser extent compared to the powder suspension, with a maximum $\mathrm{pH}$ of 6 . For carboxylate-modified apatite, a rapid decrease in $\mathrm{pH}$ is first observed, especially for c-HAp, followed by a slow increase to 5.5 and 5.2 for a-HAp and c- 
HAp, respectively. These values are significantly smaller than the equilibrium pHs obtained for the corresponding powder suspension in the absence of lead and than HAp in the presence of lead. In contrast, in the case of NTP, equilibrium pHs are higher than for HAp in the presence of lead and either higher (for 5N-HAp) or smaller (for 2.5N-HAp) than the corresponding powder in lead-free solutions. In agreement with previous reports [4,30], the observed decrease in equilibrium $\mathrm{pH}$ for the pure HAp can be attributed to the strong affinity of the apatite surface for $\mathrm{Pb}^{2+}$, leading to the precipitation of poorly soluble hydroxypyromorphite $\left(\mathrm{Pb}_{10}\left(\mathrm{PO}_{4}\right)_{6}(\mathrm{OH})_{2}\right)$ and hence limiting apatite dissolution. In the case of carboxylates, the instant acidification of the system suggests the formation of $\mathrm{Pb}^{2+}$ complexes with carboxylic acids, releasing protons in the solution. The fact that this process is more evident with c-HAp compared to a-HAp can be due to the fact that citric acid bears more $\mathrm{COOH}$ groups and that it is present in a larger amount than adipic acid. In the case of NTP, the literature indicates that $\mathrm{Pb}^{2+}$ forms stable complexes with diand tri-deprotonated forms of this ligand (i.e. $\mathrm{Pb}\left[\left(\mathrm{H}_{2} \mathrm{O}_{3} \quad \mathrm{PCH}_{2}\right) \mathrm{N}\left(\mathrm{CH}_{2} \mathrm{PO}_{3} \mathrm{H}\right)_{2}\right]$ and $\left.\mathrm{Pb}_{2}\left[\left(\mathrm{O}_{3} \mathrm{PCH}_{2}\right) \mathrm{N}\left(\mathrm{CH}_{2} \mathrm{PO}_{3} \mathrm{H}\right)_{2}\right]\right)$ [31]. As indicated above, main NTP forms at $\mathrm{pH} 5$ are tri- and tetra-deprotonated. Therefore, the complexation of $\mathrm{Pb}^{2+}$ by NTP is expected to induce a protonation of the ligand, and therefore an increase in $\mathrm{pH}$. As a result, the $\mathrm{pH}$ evolution results from a balance between lead-apatite interactions (decreasing $\mathrm{pH}$ ) and lead-NTP interactions (increasing $\mathrm{pH}$ ). The second process is expected to become more predominant as the amount of NTP associated with HAp increases, explaining the observed difference between $2.5 \mathrm{~N}$ - and $5 \mathrm{~N}$ HAp. Noticeably, these results support the recent results obtained by Kang on thiol-modified silica spheres that demonstrated the key importance of the acido-basic properties of the organomineral surface on the material capacity for $\mathrm{Pb}^{2+}$ retention [32].

\section{Conclusions}


In situ incorporation of organic ligands within apatite structures provides a simple method to prepare nano-sized powders with very high sorption capacity for $\mathrm{Pb}^{2+}$. Because they can be incorporated in significant amount (up to $8 \mathrm{wt} \%$ ), carboxylic acids are particularly suitable to achieve such performances. However, their affinity for lead ions is weaker than that of the apatite surface. In contrast, the here-evaluated aminophosphonate exhibits good affinity for $\mathrm{Pb}^{2+}$ but they can only be present in small amounts (maximum $3 \mathrm{wt} \%$ ) using our process. Indeed, lead ions represent a particular case because pure apatite already exhibits a significant affinity for these metals. Hence the potentialities of here-described materials may appear even more clearly for other cations, such as $\mathrm{Cd}^{2+}$ and $\mathrm{Zn}^{2+}$, that interact less strongly with the mineral phase. In parallel, additives bearing both carboxylate and phosphonate functions may be evaluated in the future to improve further the sorption capacity of these materials. However, these possible improvements will have to be balanced with the benefits of using cheap, non-toxic ligands such as citric acid, adipic acid and NTP.

\section{ACKNOWLEDGMENTS}

S. S. thanks the FSP-ARESM program for funding her stay in Paris. 


\section{REFERENCES}

[1] V.K. Gupta, P.J.M. Carrott, M.M.L. Ribeiro Carrott, Suhas, Low cost adsorbents: growing approach to wastewater treatment - a review, Crit. Rev. Environ. Sci. Technol. 39 (2009) 783-842.

[2] A. Dybowska, D.A.C. Manning, M.J. Collins, T. Wess, S. Woodgate, E. Valsami-Jones, An evaluation of the reactivity of synthetic and natural apatites in the presence of aqueous metals, Sci. Tot. Environ. 407 (2009) 2953-2965.

[3] A. Nzihou, P. Sharrock, Role of phosphate in the remediation and reuse of heavy metal polluted wastes and sites, Waste Biomass. Valor. 1 (2010) 163-174.

[4] E. Valsami-Jones, K.V. Ragnarsdottir, A. Putnis, D. Bosbach, A.J. Kemp, G. Cressey, The dissolution of apatite in the presence of aqueous metal cations at $\mathrm{pH} 2-7$, Chem. Geol. 151 (1998) 215-233.

[5] H. Bouyarmane, S. El Asri, A. Rami, C. Roux, M.A. Mahly, A. Saoiabi, T. Coradin, A. Laghzizil, Pyridine and phenol removal using natural and synthetic apatites as low cost sorbents: Influence of porosity and surface interactions, J. Hazard. Mater. 181 (2009) 736741.

[6] X. Cao, L.Q. Ma, D.R. Rhue, C.S. Appel, Mechanisms of lead, copper, and zinc retention by phosphate rock, Environ. Pollut. 131 (2004) 435-444.

[7] S. El Asri, A. Laghzizil, T. Coradin, A. Saoiabi, A. Alaoui, R. M'hamedi, Conversion of natural phosphate rock into mesoporous hydroxyapatite for heavy metals removal from aqueous solution, Colloid Surf. A: Physicochem. Eng. Aspects 362 (2010) 33-38.

[8] S.V. Dorozhkin, Nanodimensional and Nanocrystalline Apatites and Other Calcium Orthophosphates in Biomedical Engineering, Biology and Medicine, Materials 2 (2009) 
1975-2045.

[9] Y. Liu, G.H. Nancollas, Crystallization and colloidal stability of calcium phosphate phases, J. Phys. Chem. B 101 (1997) 3464-3468

[10] Z. Amjad, The influence of polyphosphates, phosphonates, and poly(carboxylic acids) on the crystal growth of hydroxyapatite, Langmuir 3 (1987) 1063-1069.

[11] L. El Ahmmari, H. Marroun, A. Laghzizil, A. Saoiabi, C. Roux, J. Livage, T. Coradin, Organically modified porous hydroxyapatites : a comparison between alkylphosphonate grafting and citrate chelation., J. Solid State Chem. 181 (2008) 848-854.

[12] A. Zieba, G. Sethuraman, F. Perez, G.H. Nancollas, D. Cameron, Influence of organic phosphonates on hydroxyapatite crystal growth kinetics, Langmuir 12 (1996) 2853-2858.

[13] A. Aissa, M. Debbabi, M. Gruselle, R. Thouvenot, P. Gredin, R. Traksmaa, K. Tonsuaadu, Covalent modification of calcium hydroxyapatite surface by grafting phenyl phosphonate moieties, J Solid State Chem. 180 (2007) 2273-2278.

[14] A. Bouladjine, A. Al-Kattan, P. Dufour, C. Drouet, New advances in nanocrystalline apatite colloids intended for cellular drug delivery, Langmuir 25 (2009) 12256-1265.

[15] M.R.T. Filgueiras, D. Mkhonto, N.H. de Leeuw, Computer simulations of the adsorption of citric acid at hydroxyapatite surfaces, J. Cryst. Growth 294 (2006) 60-68.

[16] A. López-Macipe, J. Gómez-Morales, R. Rodríguez-Clemente, Nanosized hydroxyapatite precipitation from homogeneous calcium/citrate/phosphate solutions using microwave and conventional heating, Adv. Mater. 10 (1998) 49-53.

[17] K. Achelhi, S. Masse, G. Laurent, A. Saoiabi, A. Laghzizil, T. Coradin, Role of carboxylate chelating agents on the chemical, structural and textural properties of hydroxyapatite, Dalton Trans. 39 (2010) 10644-10651. 
[18] R.K. Cannan, A. Kibrick, Complex formation between carboxylic acids and divalent cations, J. Am. Chem. Soc. 60 (1938) 2314-2320.

[19] A. Cabeza, X. Ouyang, C.V.K. Sharma, M.A.G. Aranda, S. Bruque, A. Clearfield, Complexes formed between Nitrilotris(methylenephosphonic acid) and $\mathrm{M}^{2+}$ transition metals: Isostructural organic-inorganic hybrids, Inorg. Chem. 41 (2002) 2325-2333.

[20] K.D. Demadis S.D. Katarachia M. Koutmos, Crystal growth and characterization of zinc(amino-tris-(methylenephosphonate) organic-inorganic hybrid networks and their inhibiting effect on metallic corrosion, Inorg. Chem. Commun. 8 (2005) 254-258.

[21] A. Bahdod, S. El Asri, A. Saoiabi, T. Coradin, A. Laghzizil, Adsorption of phenol from an aqueous solution by selected apatite adsorbents: kinetic process and impact of the surface properties, Water Res. 43 (2009) 313-318.

[22] S. Saoiabi, S. El Asri, A. Laghzizil, T. Coradin, K. Lahlil, Nanoporous surface of organofunctionalized hydroxyapatite fabricated from phosphate rock, Mater. Lett. 64 (2010) 2679-2681

[23] Y.S. Ho, Review of second-order models for adsorption systems, J. Hazard. Mater. 136 (2006) 681-689.

[24] J. Dron, A. Dodi, Comparison of adsorption equilibrium models for the study of $\mathrm{Cl}^{-}, \mathrm{NO}_{3}{ }^{-}$ and $\mathrm{SO}_{4}{ }^{2-}$ removal from aqueous solutions by an anion exchange resin, J. Hazard. Mater. 190 (2011) 300-307.

[25] H.S. Martinez-Tapia, A. Cabeza, S. Bruque, P. PertierraS. Garcia-Granda, M.A.G. Aranda, Synthesis and structure of $\mathrm{Na}_{2}\left[\left(\mathrm{HO}_{3} \mathrm{PCH}_{2}\right)_{3} \mathrm{NH}\right] 1.5 \mathrm{H}_{2} \mathrm{O}$ : The first alkaline triphosphonate, $\mathrm{J}$ Solid State Chem. 151 (2000) 122-129.

[26] T. Sasaki, Y. Sakai, A. Iizuka, T. Nakae, S. Kato, T. Kojima, A. Yamasaki, Evaluation of the capacity of hydroxyapaptite prepared from concrete sludge to remove lead from water, Ind. 
Eng. Chem. Res. 50 (2011) 9564-9568

[27] A. Bengtsson, S. Sjöberg, Surface complexation and proton-promoted dissolution in aqueous apatite systems, Pure Appl. Chem. 81 (2009) 1569-1584.

[28] E.C. Reynolds, P.F. Ripley, E. Storey, Phosphoprotein inhibition of hydroxyapatite dissolution, Calcif. Tissue Int. 34 (1982) S52-56

[29] R. Pairat, C. Sumeath, F.H. Browning, H.S. Fogler, Precipitation and dissolution of calciumATMP precipitates for the inhibition of scale formation in porous media, Langmuir 13 (1997) 1791-1798.

[30] S. Baillez, A. Nzihou, D. Bernache-Assolant, E. Champion, P. Sharrock, Removal of aqueous lead ions by hydroxyapatites: Equilibria and kinetic processes, J. Hazard. Mater. 139 (2007) 443-446.

[31] A. Cabeza, M.A.G. Aranda, S. Bruque, New lead triphosphonates: synthesis, properties and crystal structures, J. Mater. Chem. 9 (1999) 571-578.

[32] K.-S. Kang, The cause of highly efficient lead removal with silica spheres modifying the surface by a base catalyst, Ind. Eng. Chem. Res. 51 (2012) 4101-4104. 
Table 1. Main chemical and structural features of pure apatite (HAp) and organo-apatite powders. Calcium-phosphorus atomic ratio $(\mathrm{Ca}: \mathrm{P})$, carbon content $(\% \mathrm{C})$, nitrogen content $(\% \mathrm{~N})$, organic content and specific surface area $\left(S_{B E T}\right)$

\begin{tabular}{cccccc}
\hline Ca:P & $\begin{array}{c}\% \mathrm{C}^{\mathrm{b}} \\
(\mathrm{wt} \%)\end{array}$ & $\begin{array}{c}\% \mathrm{~N}^{\mathrm{b}} \\
(\mathrm{wt} \%)\end{array}$ & $\begin{array}{c}\text { Organic } \\
(\mathrm{wt} \%)\end{array}$ & $\begin{array}{c}S_{B E T} \mathrm{e}^{\mathrm{e}} \\
\left(\mathrm{m}^{2} \cdot \mathrm{g}^{-1}\right)\end{array}$ \\
\hline HAp & 1.60 & 0.3 & - & $<1$ & 140 \\
$\mathrm{a}-\mathrm{HAp}$ & 1.69 & 2.7 & - & $4^{\mathrm{c}}$ & 160 \\
c-HAp & 1.61 & 4.7 & - & $8^{\mathrm{c}}$ & 155 \\
2.5N-HAp & 1.58 & 0.7 & 0.15 & $2^{\mathrm{d}}$ & 160 \\
$5 \mathrm{~N}-\mathrm{HAp}$ & 1.60 & 0.8 & 0.30 & $3^{\mathrm{d}}$ & 125 \\
\hline${ }^{\mathrm{a}} \pm 0.01$, from & ICP-AES; ${ }^{\mathrm{b}} \pm 0.05 \mathrm{wt} \%$, from elemental analysis; ${ }^{\mathrm{c}} \pm 0.5 \mathrm{wt} \%$, from $\mathrm{TGA}$
\end{tabular}
weight loss in the $200-500^{\circ} \mathrm{C}$ range, ${ }_{ \pm} \pm 0.5 \mathrm{wt} \%$, from TGA weight loss in the $300^{\circ}-700^{\circ} \mathrm{C}$ range; ${ }_{ \pm} 5 \mathrm{~m}^{2} \cdot \mathrm{g}^{-1}$, from $\mathrm{N}_{2}$ isotherms using the BET model 
Table 2. Lead sorption properties pure apatite (HAp) and organo-apatite powders. Sorption at equilibrium $\left(q_{e}\right)$, sorption pseudo-first order constant $(k)$ and correlation coefficient $\left(R^{2}{ }_{k i n}\right)$ from Lagergren pseudo first order modeling of kinetics data (lead concentration $=100 \mathrm{mg} \cdot \mathrm{mL}^{-1}$ ); maximum capacity $\left(q_{e, \max }\right)$, equilibrium constant $\left(K_{F}\right)$, interaction parameter $(\beta)$ and correlation coefficient $\left(R^{2}{ }_{i s o}\right)$ from Freundlich modeling of isothermal sorption data.

\begin{tabular}{|c|c|c|c|c|c|c|c|}
\hline & $\begin{array}{c}q_{e} \\
\left(\mathrm{mg}^{-1}\right)\end{array}$ & $\begin{array}{c}k \\
\left(\mathrm{~s}^{-1}\right)\end{array}$ & $R_{k i n}^{2}$ & $\begin{array}{c}q_{e, \max } \\
\left(\mathrm{mg}^{-1}\right)\end{array}$ & $K_{F}$ & $\beta$ & $R_{\text {iso }}^{2}$ \\
\hline HAp & $46 \pm 2$ & $\begin{array}{c}0.020 \\
\pm 0.002\end{array}$ & 0.99 & $240 \pm 10$ & $\begin{array}{c}0.17 \\
\pm 0.05\end{array}$ & $0.9 \pm 0.2$ & 0.99 \\
\hline a-HAp & $50 \pm 1$ & $\begin{array}{c}0.500 \pm \\
0.025\end{array}$ & 0.99 & $1200 \pm 200$ & $\begin{array}{c}0.20 \\
\pm 0.03\end{array}$ & $0.3 \pm 0.1$ & 0.99 \\
\hline c-HAp & $50 \pm 1$ & $\begin{array}{c}0.455 \\
\pm 0.025\end{array}$ & 0.99 & $900 \pm 50$ & $\begin{array}{c}0.24 \\
\pm 0.03\end{array}$ & $0.3 \pm 0.1$ & 0.99 \\
\hline 2.5N-HAp & $47 \pm 1$ & $\begin{array}{c}0.078 \\
\pm 0.005\end{array}$ & 0.99 & $440 \pm 30$ & $\begin{array}{c}0.11 \\
\pm 0.04\end{array}$ & $0.9 \pm 0.2$ & 0.99 \\
\hline 5N-HAp & $48 \pm 1$ & $\begin{array}{c}0.079 \\
\pm 0.044\end{array}$ & 0.99 & $450 \pm 30$ & $\begin{array}{c}0.09 \\
\pm 0.04\end{array}$ & $0.6 \pm 0.2$ & 0.99 \\
\hline
\end{tabular}




\section{Figure captions}

Figure 1. Thermogravimetric curves for pure apatite (HAp) and organo-apatites powders

Figure 2. XRD patterns for pure apatite (HAp) and organo-apatites powders

Figure 3. FTIR spectra for pure apatite (HAp) and organo-apatites powders

Figure 4. TEM images of (a) HAp, (b) a-HAp, (c) c-HAp, (d) 2.5N-HAp, (e) 5N-HAp (scale bar $=100 \mathrm{~nm}),(\mathrm{f})$ HRTEM image of $5 \mathrm{~N}-\mathrm{HAp}($ scale bar $=10 \mathrm{~nm})$

Figure 5. $\mathrm{N}_{2}$-sorption isotherms for pure apatite (HAp) and organo-apatites powders

Figure 6. Kinetics of $\mathrm{Pb}^{2+}$ sorption from aqueous solutions $(\mathrm{pH}$ 5) by pure apatite ( $\mathrm{HAp})$ and organo-apatites powders. Plain lines correspond to the fitting of experimental data using the Lagergren pseudo-first order model

Figure 7. Sorption isotherms of $\mathrm{Pb}^{2+}$ from aqueous solutions ( $\mathrm{pH}$ 5) by pure apatite (HAp) and organo-apatites powders. Plain lines correspond to the fitting of experimental data using the Freundlich model

Figure 8. Time evolution of the $\mathrm{pH}$ of pure apatite (HAp) and organo-apatites powder suspensions in aqueous solution ( $\mathrm{pH}$ 5)

Figure 9. Time evolution of the $\mathrm{pH}$ of pure apatite (HAp) and organo-apatites powder suspensions in $\mathrm{Pb}^{2+}$-containing aqueous solution ( $\mathrm{pH}$ 5) 
Figure 1

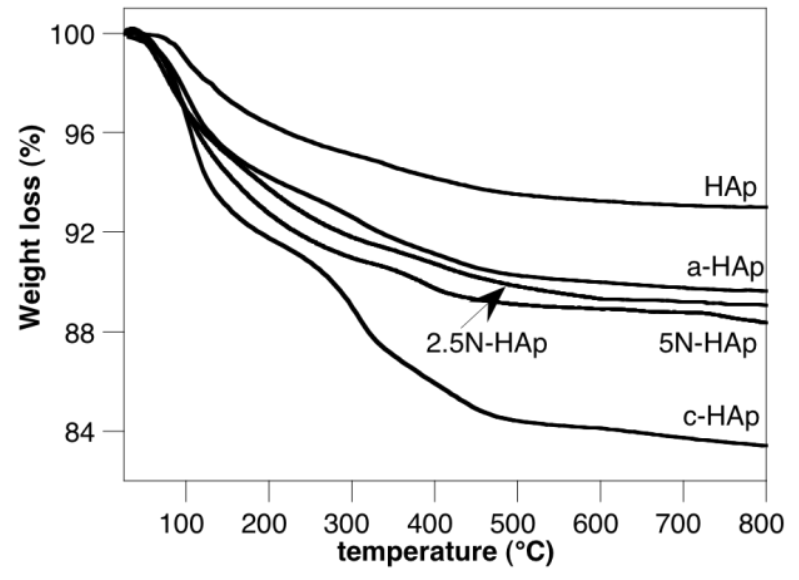


Figure 2

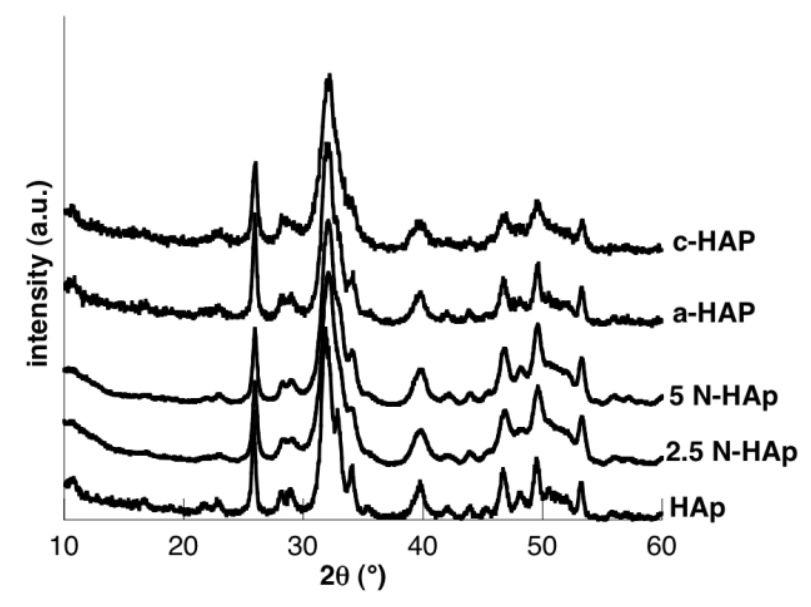


Figure 3

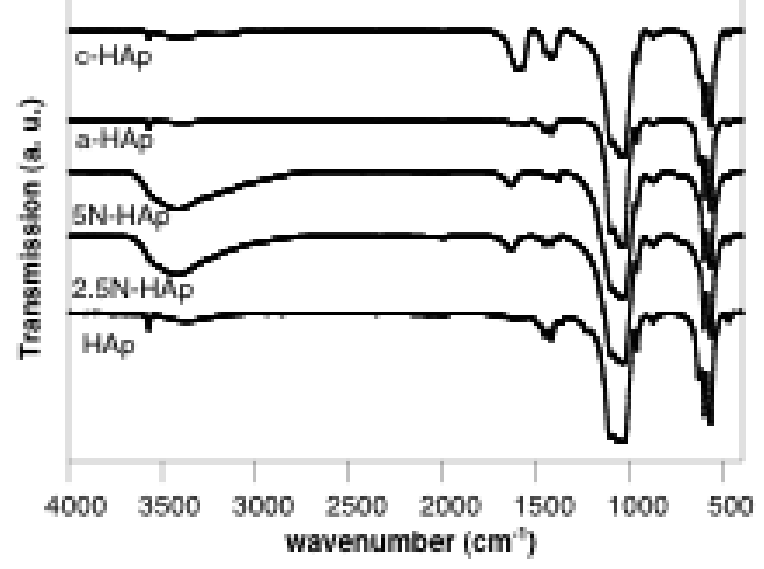


Figure 4

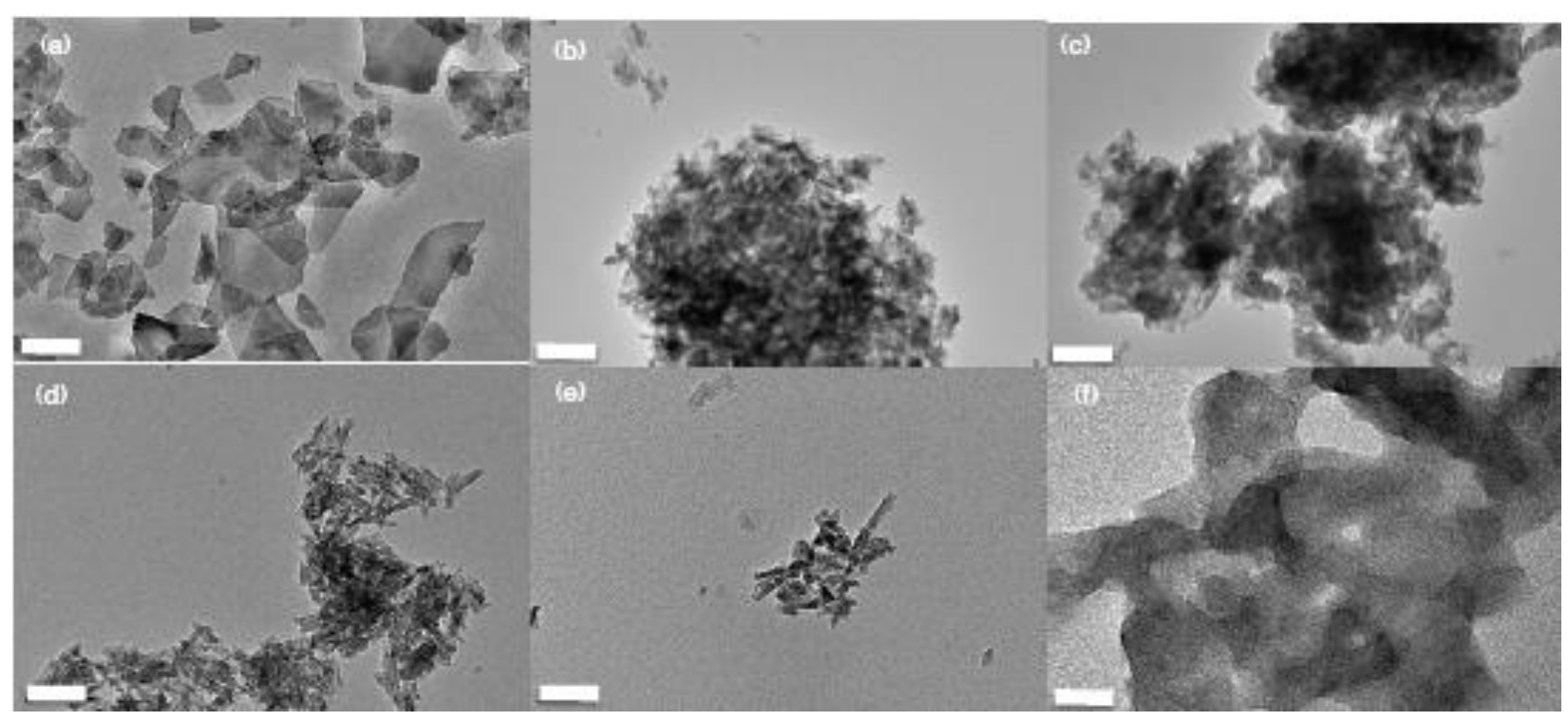


Figure 5

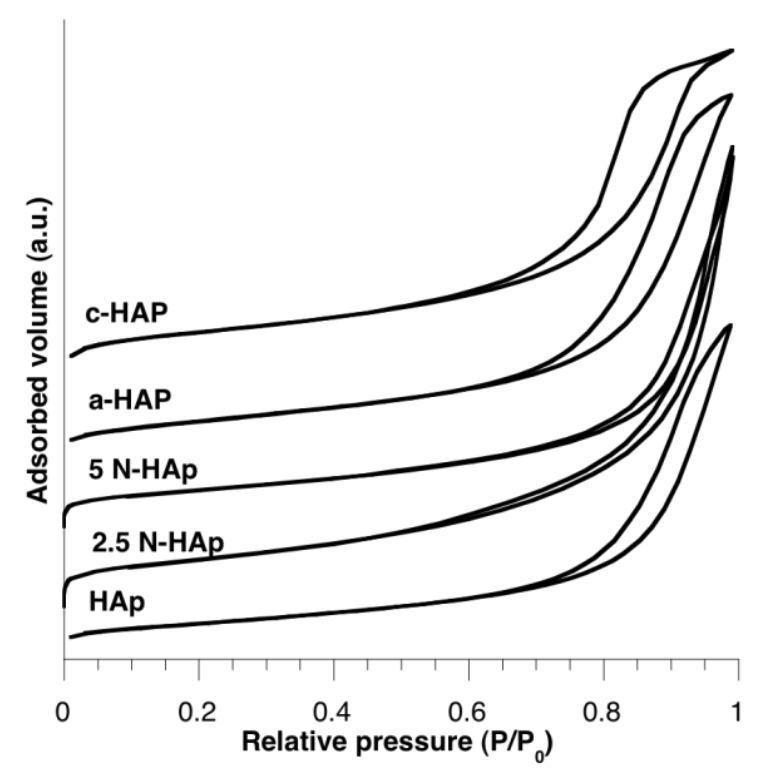


Figure 6

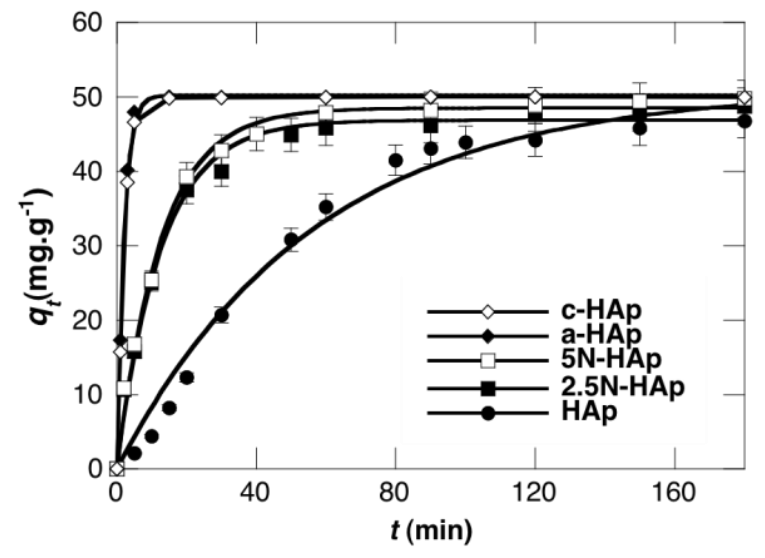


Figure 7

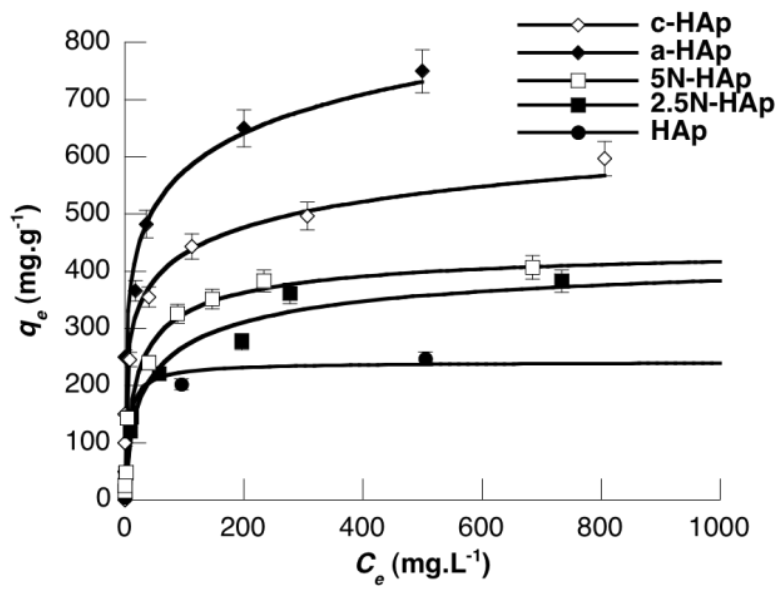


Figure 8

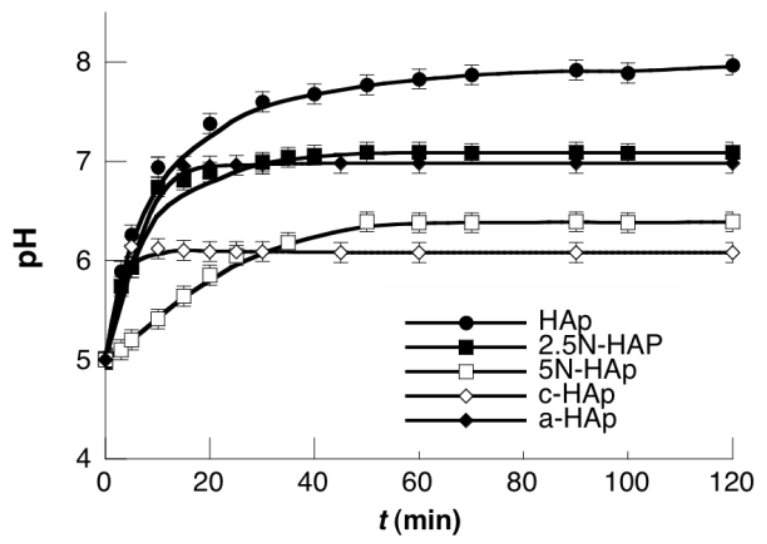


Figure 9

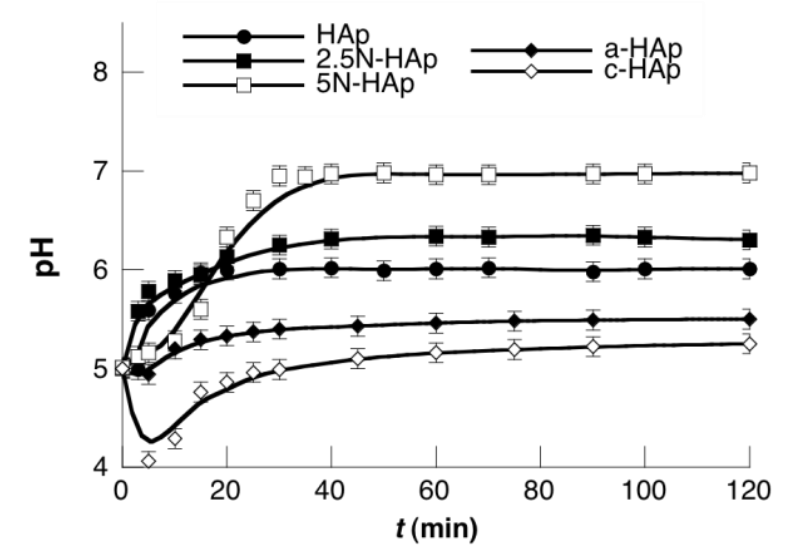

